\title{
Fantasias sexuais
}

Maria Isabel Cavalcanti*

Já disse Eça de Queiroz que a "ilusão é tão útil quanto a certeza". De fato falar, sonhar e fantasiar é próprio do ser humano e, possivelmente, o homem é o único ser sobre a terra capaz de desenvolver tais habilidades. É a força da imaginação criadora que enriquece o mundo da arte, da ciência e dos amantes refinados.

Porque se sonha? Que utilidade terá na vida humana, a Fantasia?

É preciso entender que a fantasia não é simplesmente a antítese da realidade, mas o enriquecimento desta realidade. Este enriquecimento poderá se traduzir tanto na esperança de um mundo melhor, quanto se transformar na compulsão neurótica, que destrói e que mutila.

Fantasiamos eventos, passeios, empregos novos, encontros e toda sorte de trabalhos que desejamos desempenhar, da mesma forma que fantasiamos fracassos ou crimes cruéis.

De um modo geral, há uma necessidade intrínseca de que o próprio planejamento científico venha acompanhado das cores da fantasia criadora. Para o artista principalmente, a fantasia é não só útil, mas, fundamental para execução de sua obra. Através da imaginação, o artista antevê magicamente a sua realida-

* Psicóloga clínica, educadora e terapeuta sexual. 
de e a ordena de forma gratificante. Ela antecipa a ação, favorecendo seus desejos mais íntimos, num caleidoscópio de cores, de imagens ou de sons.

$\mathrm{O}$ artista, portanto, plasma a sua obra através de sonhos que nos maravilham, da mesma forma que os inventores imaginam mil vezes, novos modelos e novas propostas que irão facilitar a vida prática. Fantasiando eles modificam o mundo e o enriquecem.

A fantasia, o sonho, o sonhador, são pois elementos necessários e indispensáveis ao existir humano. Muitos de nós entramos em clima de verdadeira ansiedade, quando nos permitimos fantasiar, temerosos do autoconceito de traição.

Fechamo-mos em nosso mundo particular e afastamos pressurosos nossas fantasias, sem discuti-las com nossos parceiros, o que resulta no empobrecimento da relação do casal. É evidente que neste ponto, o parceiro romântico e fantasioso teme o julgamento apressado do companheiro pobre e preconceituoso.

"Você não está satisfeita com minha aparência? Com nossa casa? Com nossa vida? Com meus carinhos?"

Fazem com isso uma verdadeira confusão entre fantasia e realidade. Ora, a fantasia sexual só é valida enquanto permanecer como fantasia. Partiu para a realidade deixa de ser fantasia, assumindo muitas vezes um padrão anti-social e prejudicial. Uma fantasia de violência não terá o propósito de ser vivenciada realisticamente.

A experiência da violência é a forma mais dramática de mutilar esse tipo de fantasia. Experimentar a fantasia de nos isolarmos numa praia deserta com nosso parceiro, não significa que ficaríamos felizes se, na realidade, ficássemos perdidos numa tal praia.

Mas além do aspecto inusitado da fantasia, é preciso ficar claro também que ela seja rica e variada. Compulsão numa mesma fantasia nos aprisiona e foge ao seu propósito. Isto significa que embora muitas vezes a fantasia possa abrir horizontes, em outras ocasiões ela é apenas um refúgio em que nos escondemos, quando o futuro se nos apresenta sem esperanças e a realidade cruel nos obriga a recuar como mecanismo de defesa contra a angústia e a dor.

Por isso, muitas vezes, essa alternativa torna-se neurótica, transformando pessoas saudáveis em sonhadoras habituais, onde amigos imaginários e sonhos românticos o protejem de futuras perdas e traições. Tornam-se então Viciados em Fantasia.

De fato, como diz Rafael Barret: "Desprender-se de uma realidade não é nada; o heróico é desprender-se de um sonho". Isto é válido principalmente quando a pessoa faz desse sonho a única forma de sobrevivência afetiva e sexual. Elaboram fantasias de sexo para obter o prazer que a vida lhes nega.

Imaginam carinhos e situações de ternura para suprir sua imensa carência afetiva. E, da mesma forma que a compulsão fantasiosa pode preju- 
dicar o indivíduo, isolando-o da realidade, poderá também afetar terceiros, uma vez que esta seja a estratégia para evitar o contato com o companheiro real. Neste caso, a única forma de satisfação prazerosa torna-se os estímulos mentais imaginários.

Mostra-se com isso a incapacidade pessoal de reagir aos estímulos normais do corpo e às carícias do outro.

Este é um tipo de fantasia mórbida e egoísta, que infelizmente vem sendo alimentada por uma infinidade de publicações sensacionalistas e por um "pornoshopismo" que só visam lucro e exploração. Num mundo de consumismo desenfreado não tem sido difícil desencaminhar pessoas para fantasias doentias, em nome de um falso e prejudicial modismo. Há portanto uma infinidade de tipos de fantasias; as boas e as más.

E, descrever toda sorte de fantasias eróticas é uma pretensão impossível de se realizar, uma vez que a imaginação humana flui e reflui, nos pondo em contato com padrões bizarros de comportamentos que nada tem a ver com a previsibilidade dos eventos reais do mundo concreto.

Interessante é que as fantasias não se submetem a padrões rígidos de controle e por isso mesmo não é fácil afastá-las a nosso bel prazer. Tentamos mudar muitas vezes, fantasias negativas em fantasias positivas, mas só pessoas bem estruturadas poderão fazê-lo com sucesso. Este, por sinal, é um belo exercício cognitivo.

Há fantasias padronizadas, como há fantasias mais comuns a um determinado sexo. Há fantasias que obedecem aos ditames culturais, como há fantasias que fogem a todos os padrões previsíveis.

Nossas avós trouxeram para seus sonhos figuras de um Rodolfo Valentino ou de uma Greta Garbo; a minha geração sonhou com um Clark Gable ou uma Vivien Leigh, nas paisagens de um... "E o Vento Levou...".

Hoje há sonhos, talvez mais variados, mas nem por isso menos interessantes ou prosaicos. Figuras como a de Carla Peres ou de um ET, podem provocar as fantasias eróticas dos sonhadores modernos. Homens que sonham se travestindo, ou mulheres que fantasiam seus maridos em roupas íntimas femininas.

Há fantasias que excitam e outras que fazem rir por suas extravagâncias ou esquisitices. Cada um de nós responde de forma particular a suas fantasias.

Há fantasias próprias de mulheres, como há fantasias próprias de homens. Há homens que despem uma mulher ao primeiro olhar por mais agasalhada que ela se encontre, como existem outros que fantasiam possuir uma mulher que se recuse a isso, mas, que ao mesmo tempo permita o encontro sexual. É o não querer/querendo. Esta fantasia também excita muitas mulheres, na medida em que sugere a imposição cultural de que a mulher deve ser difícil na conquista e a exime também de qualquer responsabilidade ou culpa por demonstrações ativas de sexualidade. 
São imperativos culturais que teimamos em herdar e cultivar carinhosamente. A maioria das pessoas sentem-se envergonhadas ou nervosas quando são requisitadas a falar nas suas fantasias. Isto não ocorre, porém, na tradição tântrica, onde o relato das fantasias entre os parceiros é considerado uma experiência saudável e necessária para a melhoria da vida sexual dos amantes. Mostrar-se receptivo às fantasias do outro incrementa a intimidade e à cumplicidade sexual. Afinal como diz Sheila Kitzinger, "a fantasia pode ser a poesia do sexo...”. E à medida de que o homem se corticaliza, ele tende a refinar seu repertório imaginativo. Vai aos poucos, substituindo a medula pelo córtex. Não que isto implique em subestimar o fisiológico. Afinal "cultura e biologia, caminham juntas". A proposta é de enriquecimento e não de depreciação dos aspectos sexuais.

Daí, quando nos deparamos em terapia, com casais inapetentes ou de baixo conteúdo erótico, vem à tona a terapia da excitação onde o treino de fantasia represente um papel fundamental.

Sexólogos das mais variadas correntes são unânimes em endossar o treino de fantasia no seu arsenal terapêutico. Considerando a validade terapêutica da proposta, o que observamos na prática clínica é que existem pessoas que têm uma grande dificuldade imaginativa e expressam essa sua incapacidade claramente. Neste caso, a primeira providência será exercitá-las para desenvolver o hábito de fantasiar.

Na tradição tântrica há uma proposta bem interessante, que de alguma maneira se assemelha as orientações behaviouristas.

Para as pessoas que vivenciam sua sexualidade presas unicamente as sensações do corpo, é pedido que descrevam em detalhes essas sensações e os comportamentos que as desencadeiam. Poderão praticar esta experiência sozinhas ou com seu próprio companheiro. Neste caso particular, o parceiro poderá orientá-las, fazendo-as emparelhar as sensações atuais com outras vivenciadas na adolescência ou em outro momento qualquer significativo em sua vida sexual. O parceiro deverá ser paciente e aguardar a elaboração interna do seu par, que poderá ser melhor acelerada caso ele se resolva a enunciar também uma de suas fantasias, aguardando a reação do outro.

Outras formas práticas de incrementar a capacidade fantasiosa das pessoas e através de leituras ou filmes eróticos, romanceados ou não, segundo as preferências individuais.

Para isso o terapeuta poderá fazer algumas recomendações pertinentes. Na moderna terapia sexual utilizamos também a estratégia da sugestão fantasiosa, após uma experiência de relaxamento. De alguma maneira esse expediente terapêutico se assemelha a uma dessensibilização, ao mesmo tempo em que favorece a terapia de estimulação.

Após o completo relaxamento do cliente, o terapeuta, com voz suave, começa a descrever um episódio de aproximação sensual (na praia, no campo, etc. ...) e num certo momento, interrompe o relato, pedindo que o cliente continue a imaginar o resto da história. Muitas vezes, ao pedir ao cliente 
para voltar à realidade presente, o terapeuta é surpreendido com a afirmação: "logo agora, que estava no melhor da história?".

Neste caso eles devem ser estimulados a repetir a experiência em casa, sozinhos ou com seu par. Na nossa experiência clinica propomos dois tempos para o treinamento da fantasia.

Primeiro: Programação da fantasia

a) Selecionar personagens, cenários, etc.

b) Organizar o roteiro da fantasia

\section{Segundo: Criação de situações variadas}

Esta segunda etapa pode se tornar prejudicial se o cliente teimar em se tornar repetitivo em torno da mesma fantasia, permitindo-se ficar prisioneiro do mesmo tema, que o fará cair na mesma rotina insípida do dia a dia.

Outra forma de lidar com a fantasia é a partilha da fantasia.

Podemos considerá-la uma complementação da proposta anterior, mas, para que seja viável é importante que já exista um grau elevado de assertividade no casal. Neste caso, criar roteiros e histórias conjuntas poderá se tornar numa excelente maneira de reativar um relacionamento adormecido pela habituação.

É importante que se diga, contudo que isto só será possível se os elementos do par, sem nenhum constrangimento, se propuserem a revitalização do seu vinculo erótico/afetivo, sem sombras de sabotagens, nem falsidades.

Podemos dizer, com segurança, que quando existe amor de ambas as partes o caminho do sucesso estará garantido e o encontro das duas fantasias proporcionará momentos de verdadeira magia.

Afinal, é através da fantasia que os amantes criam o seu mundo particular, transformando em romance, uma simples companhia.

No amor, como na arte, a fantasia cria e recria. É evidente que, em matéria de amor, não nos reportamos à fantasias perigosas, grosseiras ou fatais, embora algumas delas sejam excitantes para algumas pessoas.

Queremos dar uma ênfase maior as fantasias românticas, que no terreno do amor formam a verdadeira "cola que mantém ligadas as relações amorosas." Quando são compartilhadas elas aproximam ainda mais o casal, explorando possibilidades, expandindo e solidificando o vínculo, uma vez que prerrogativa fundamental do amor maduro é aquela em que um total espírito de liberdade podemos refletir, repensar em enriquecer nosso repertório comum, ao mesmo tempo que ampliamos e reinventamos nossa própria identidade pessoal.

E isto está ao alcance de todo ser humano, uma vez que a capacidade de amar e de crescer no amor é inerente a todos nós. 
Com razão diz Willard Gaylim que "só o ser humano é capaz de utilizar os mecanismos do amor romântico, mediante a fantasia e a memória para manter viva a paixão amorosa, mesmo depois de passado o êxtase decorrente dos primeiros impulsos".

Daí porque se diz que a fantasia é parte integrante do romance amoroso, porque é através de seu dinamismo inovador que poderemos salvar o mundo do individualismo estéril e imediatista que tem povoado a nossa civilização de angústia, de pobreza emocional e de um doloroso egoísmo. Imbuídos desse propósito criativo e renovador, poderemos transformar o amor numa porta aberta para verdadeira liberdade, e onde ele se torne a música e a poesia, o bem e o belo, o princípio e o fim do existir humano.

\section{REFERÊNCIAS BIBLIOGRÁFICAS}

ACKERMAN, D. Uma história natural do amor, B. Brasil, RJ, 1977.

ANAND, M. A arte do extase, Ed. Campus, RJ, 1992.

CAVALCANTI \& CAVALCANTI. Tratamento clínico das inadequações sexuais, Ed. Roca, SP, 2. ed., 1997.

GAYLIN, W. Redescubriendo el amor, Sudamericana Planeta, Argentina, 1987.

GILLAN, P. A terapia sexual, Persona, SP, 1976.

KAPLAN, H. A nova terapia do sexo, Nova Fronteira, RJ, 1977.

LO PICCOLO, H. J. Descobrindo o prazer, Summus, SP, 1987.

MCCARTHY, B. O que você (ainda) não sabe sobre sexualidade masculina, Summus, SP, 1981.

SOLOMON, R. O amor, Ed. Saraiva, SP, 1992. 